\title{
Editorial
}

\section{History of otorhinolaryngology (ORL) in different European countries between 1880 and 1920}

\author{
Albert Mudry, Wolfgang Pirsig, Neil Weir
}

In the editorial of the first completely ORL journal entitled Annales des Maladies de l'Oreille et $d u$ Larynx Isambert wrote: 'Specialities are, in fact, one of the requirements, and we could also add, one of the real methods of progress in modern science. In medicine, as is the same everywhere, the division of labour has become a necessity. The time of acknowledgeable scholars is gone... Those organs that are not directly accessible to our senses are becoming one by one more accessible thanks to exploratory instruments... In conjunction with the diseases of the larynx, we are always obliged to describe those of the pharynx, the nasal fossa and of the mouth... For these different diseases, there is a common ground. ${ }^{1}$ Thus Isambert touches on the importance of having specialities in medicine, notably for organs needing special instumentation for their exposition and the need to link ear, nose and throat together because of their anatomical and pathological relationship.

The speciality of otorhinolaryngology is a product in most cases of the early 20th century; otology and laryngology had quite different origins. The early otologists were surgeons used to the scalpel and trephine whilst the early laryngologists were physicians who combined their knowledge of the larynx with that of the chest. The link between the two, namely rhinology, was embraced by the laryngologists. The two separate disciplines had their own practitioners, departments and journals and only came together, with some exceptions, in the first quarter of the 20th century. ${ }^{2}$ The union of the specialities varied from one European country to another.

The aim of this study is to trace the development of otology, laryngology and subsequently otorhinolaryngology particularly between the years 1880 and 1920. It was during this time that ORL became an autonomous speciality, that the first university ORL departments were created and national ORL societies were founded. The idea for this project started in 1999 and was firstly expressed as a poster exhibition during the EUFOS (European
Federation of ORL Societies) congress in Berlin in May 2000 under the initiation and supervision of Professor Wolfgang Pirsig. Sixteen countries participated with great success. More European countries have now joined in and 31 are now represented in this Journal of Laryngology \& Otology supplement which has been realized with the generous financial support of the A. Charles Holland Foundation.

The concept is straightforward; each country presents its own ORL history between 1880 and 1920. The results are fascinating and exceptional in the variability between countries. Different factors can explain the variation such as the existence of a medical faculty, the political stability, the socioeconomic level and the technological opportunities. Behind these facts, though, were human beings with their own history and their own particularities. No country was better than another. All the texts were written by ORL specialists, not all of whom are historians. Apart from general guidelines, each author was free to present his story as he wished. This explains the variety and diversity of structure of each text and to some extent the difference in interpretation of main historical landmarks. The history of ORL was in a sense a reflection of the state of each country during this period of time.

ORL found its direction during the period of 1880 to 1920 . The acceptance of ORL as a speciality was made clear in 1910 in a Presidential Address given to the Section of Laryngology of the Royal Society of Medicine by Patrick Watson Williams and reported in The Journal of Laryngology, Rhinology and Otology, the first English speaking ORL journal published since 1887: "We hear it said that this is a day of specialism, and specialism in medicine and surgery is thought to be a modern development...No one could be more opposed to too early or too narrow specialisation than I am, for it is certain that a sound up-bringing in the whole range of general medicine and surgery is the only safe foundation for any special branch...But things are very different from what they were when I started practice, and 
hardly any individual is capable of a complete mastery of the whole range of rhino-laryngology, and if otology be superadded the ground is so extensive, that without devoting his whole time and attention to these subjects over several years, no one can hope to be a scientific expert throughout such a large territory'. ${ }^{3}$ (Watson Williams's department in the University of Bristol had by 1910 already united rhinolaryngology with otology).

The speciality of ORL was created out of fusion of the disciplines of otology and rhinolaryngology. With increasing knowledge and complexity of the subject there has in the last 40 years been again a subdivision in specialization. ${ }^{2}$ ORL is though an important speciality which carries the ability to effect optimal health in the vital area of communication, the leitmotiv of the 21st century.

\section{Acknowledgements}

The editors wish to extend their thanks to Mrs Daphne Field for her major contribution to the production of this work, to Mrs Jennifer Almond for copyediting the text and to Delia Siedle and Faye Cheeseman of RSM Press. We are extremely grateful to $\mathrm{Mr} \mathrm{H}-\mathrm{P}$ Weihmann, from the A. Charles Holland Foundation, Switzerland, for his support.

\section{References}

1 Isambert E, Krishaber M, Ladreit de Lacharrière J. A nos lecteurs. Ann Mal Oreille Larynx 1875;1:1-9

2 Weir N. Otolaryngology - an Illustrated History. London: Butterworths, 1990; 1, 8

3 Williams W. The education of the specialist in laryngology, rhinology and otology. $J$ Laryngol Rhinol Otol 1910;25:619-23 